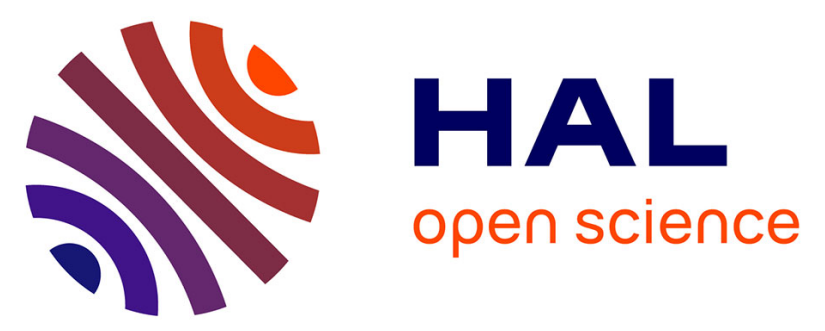

\title{
The QUIDAM study: Hydroquinidine therapy for the management of Brugada syndrome patients at high arrhythmic risk
}

Antoine Andorin, Jean-Baptiste Gourraud, Jacques Mansourati, Swanny

Fouchard, Herve Le Marec, Philippe Maury, Philippe Mabo, Jean-Sylvain

Hermida, Jean-Claude Deharo, Béatrice Delasalle, et al.

\section{To cite this version:}

Antoine Andorin, Jean-Baptiste Gourraud, Jacques Mansourati, Swanny Fouchard, Herve Le Marec, et al.. The QUIDAM study: Hydroquinidine therapy for the management of Brugada syndrome patients at high arrhythmic risk. Heart Rhythm, 2017, 14 (8), pp.1147-1154. 10.1016/j.hrthm.2017.04.019 . hal-01760741

\section{HAL Id: hal-01760741 \\ https://hal.science/hal-01760741}

Submitted on 11 Jul 2018

HAL is a multi-disciplinary open access archive for the deposit and dissemination of scientific research documents, whether they are published or not. The documents may come from teaching and research institutions in France or abroad, or from public or private research centers.
L'archive ouverte pluridisciplinaire HAL, est destinée au dépôt et à la diffusion de documents scientifiques de niveau recherche, publiés ou non, émanant des établissements d'enseignement et de recherche français ou étrangers, des laboratoires publics ou privés. 


\section{Accepted Manuscript}

The QUIDAM Study: hydroquinidine therapy in the management of Brugada syndrome patients at high arrhythmic risk

Antoine Andorin, MD, Jean-Baptiste Gourraud, MD, PhD, Jacques Mansourati, MD, Swanny Fouchard, PhD, Hervé le Marec, MD, PhD, Philippe Maury, MD, Philippe

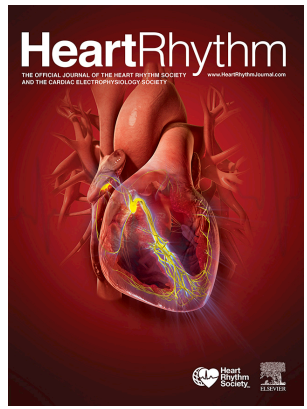
Mabo, MD, PhD, Jean-Sylvain Hermida, MD, Jean-Claude Deharo, MD, Beatrice Delasalle, MS, Simon Esnault, MD, Nicolas Sadoul, MD, Jean-Marc Davy, MD, PhD, Antoine Leenhardt, MD, Didier Klug, MD, Pascal Defaye, MD, Dominique Babuty, $\mathrm{MD}, \mathrm{PhD}$, Frédéric Sacher, MD, Vincent Probst, MD, PhD

PII: S1547-5271(17)30445-9

DOI: 10.1016/j.hrthm.2017.04.019

Reference: HRTHM 7121

To appear in: Heart Rhythm

Received Date: 28 December 2016

Please cite this article as: Andorin A, Gourraud J-B, Mansourati J, Fouchard S, le Marec H, Maury P, Mabo P, Hermida J-S, Deharo J-C, Delasalle B, Esnault S, Sadoul N, Davy J-M, Leenhardt A, Klug D, Defaye P, Babuty D, Sacher F, Probst V, The QUIDAM Study: hydroquinidine therapy in the management of Brugada syndrome patients at high arrhythmic risk, Heart Rhythm (2017), doi: 10.1016/ j.hrthm.2017.04.019.

This is a PDF file of an unedited manuscript that has been accepted for publication. As a service to our customers we are providing this early version of the manuscript. The manuscript will undergo copyediting, typesetting, and review of the resulting proof before it is published in its final form. Please note that during the production process errors may be discovered which could affect the content, and all legal disclaimers that apply to the journal pertain. 
The QUIDAM Study: hydroquinidine therapy in the management of Brugada syndrome patients at high arrhythmic risk

Antoine Andorin $^{1 *}, \mathrm{MD}$; Jean-Baptiste Gourraud ${ }^{1 *}, \mathrm{MD}, \mathrm{PhD} ; \mathrm{Jacques}^{\text {Mansourati }}{ }^{2}$, MD; Swanny Fouchard ${ }^{1}, \mathrm{PhD}$; Hervé le Marec ${ }^{1}, \mathrm{MD}, \mathrm{PhD}$; Philippe Maury ${ }^{3}, \mathrm{MD}$; Philippe $\mathrm{Mabo}^{4}, \mathrm{MD}, \mathrm{PhD}$; Jean-Sylvain Hermida ${ }^{5}$, MD; Jean-Claude Deharo ${ }^{6}$, MD; Beatrice Delasalle ${ }^{1}$, MS; Simon Esnault, MD ${ }^{1}$; Nicolas Sadoul, MD $^{7}$; Jean-Marc $\operatorname{Davy}^{8}, \mathrm{MD}, \mathrm{PhD}$; Antoine Leenhardt ${ }^{9}, \mathrm{MD}$; Didier Klug ${ }^{10}$, MD; Pascal Defaye ${ }^{11}$, MD; Dominique Babuty ${ }^{12}$, MD, PhD; Frédéric Sacher ${ }^{13}$, MD and Vincent Probst, $\mathrm{MD}, \mathrm{PhD}^{1}$

${ }^{1}$ L'institut du thorax, INSERM, CNRS, UNIV Nantes, CHU Nantes, Nantes, France

${ }^{2}$ CHU Brest, Service de cardiologie, Brest, France

${ }^{3} \mathrm{CHU}$ Toulouse, Service de cardiologie, Toulouse, France

${ }^{4}$ CHU Rennes, Service de cardiologie, Rennes, France

${ }^{5}$ CHU Amiens, Service de cardiologie, Amiens, France

${ }^{6}$ CHU Marseille, Service de cardiologie, Marseille, France

${ }^{7}$ CHU Nancy, Service de cardiologie, Nancy, France

${ }^{8}$ CHU Montpellier, Service de cardiologie, Montpellier, France

${ }^{9}$ CNMR Maladies Cardiaques Héréditaires Rares, Hôpital Bichat; Université Paris

Diderot, Sorbonne Paris Cité; AP-HP, Service de Cardiologie, Hôpital Bichat, Paris, France.

${ }^{10}$ CHU Lille, Service de cardiologie, Lille, France

${ }^{11}$ CHU Grenoble, Service de cardiologie, Grenoble, France

${ }^{12}$ CHU Tours, Service de cardiologie, Tours, France 
${ }^{13}$ CHU Bordeaux, IHU LIRYC, INSERM 1045, Université de Bordeaux, Bordeaux, France

* These authors contributed equally to this work

Short Title: Quinidine in high-risk patients with Brugada syndrome

Corresponding author: Jean-Baptiste Gourraud, Service de Cardiologie, CHU de Nantes - Hôpital Nord -Laennec, Bvd Jacques Monod, 44093 Nantes Cedex, France;

e-mail: jeanbaptiste.gourraud@chu-nantes.fr; tel: +33-240-165-009; fax: +33-240$165-024$

Conflict of Interest: Financial and technical support from Sanofi-Aventis were provided.

Word Count: 5024 words 


\section{$\underline{\text { Abstract }}$}

Background: Although the implantable cardiac defibrillator (ICD) remains the main therapy in Brugada syndrome $(\mathrm{BrS})$, it does not reduce life-threatening ventricular arrhythmia. Based on pathophysiological mechanisms, hydroquinidine (HQ) has been suggested for the effective prevention of arrhythmia.

Objective: To provide evidence-based data supporting HQ use to prevent life threatening ventricular arrhythmia in high-risk patients with $\mathrm{BrS}$.

Methods: We performed a prospective multicentre randomised (HQ vs. placebo) doubleblind study with two 18-month cross-over phases in patients with $\mathrm{BrS}$ and implanted with an ICD.

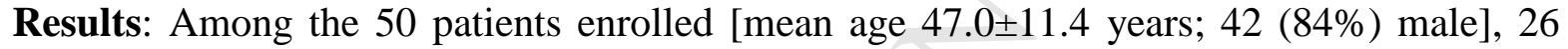
(52\%) fully completed both phases. Thirty-four (68\%) presented HQ-related side effects, mainly gastrointestinal, which led to discontinuation of the therapy in 13 (26\%). HQ has lengthened the QTc interval $(409 \pm 32$ vs. $433 \pm 37 \mathrm{~ms} ; P=0.027)$ and increased the repolarization dispersion as evaluated by the Tpe max in precordial leads $(89 \pm 15$ vs. $108 \pm 27 \mathrm{~ms} ; P<0.0001)$ with no significant changes in J-point elevation. During the 36 month follow-up, 1 appropriate ICD shock ( $0.97 \%$ event per year), 1 self-terminating ventricular fibrillation and 1 inappropriate ICD shock occurred under placebo therapy. No arrhythmic events were reported under HQ therapy.

Conclusion: Although HQ appears to be effective in preventing life-threatening ventricular arrhythmia, it could not be an alternative for ICD implant. Its frequent side effects greatly reduce its probable compliance and therefore do not reveal a significant effect. HQ increases repolarization dispersal with no changes in $\mathrm{BrS}$ pattern, which could indicate a more complex action of HQ than its $\mathrm{I}_{\mathrm{to}}$ blocking effect alone. 
Keywords: Brugada syndrome $\bullet$ Quinidine $・$ Arrhythmia $・$ Repolarisation $・$ Implantable Cardioverter Defibrillator 


\section{Introduction}

Since the first description of Brugada syndrome ${ }^{1}(\mathrm{BrS})$, our understanding of the pathophysiological mechanisms of this inherited arrhythmia disease has constantly progressed. $^{2-5}$ Although risk stratification of sudden cardiac death (SCD) has been improved in line with this understanding, ${ }^{6-8}$ management of patients affected with $\mathrm{BrS}$ remains mainly dependent on an implantable cardioverter defibrillator (ICD) with a high rate of complications. ${ }^{9}$ Bblockers were evaluated to be an alternative for ICD implant but have failed to prove their efficiency. ${ }^{10}$

Hydroquinidine (HQ), a class $\mathrm{I}_{\mathrm{A}}$ antiarrhythmic, has been used for decades in the management of arrhythmia. ${ }^{11}$ Its safety and efficacy in patients with idiopathic ventricular fibrillation $(\mathrm{VF})^{12}$, early repolarization syndrome ${ }^{2}$ or $\mathrm{BrS}$ have been reported by different retrospective studies but remain a matter of debate since it has never been investigated by randomised and multicenter studies. ${ }^{13-18}$

Our aim was to provide evidence-based data to support HQ use to prevent life threatening ventricular arrhythmia in high-risk patients with $\mathrm{BrS}$ in multicenter prospective randomised double-blind study. 


\section{Methods}

\section{Population}

Patients were recruited from February 2009 to November 2011, from 13 tertiary French university hospitals. Protocol approval was obtained from institutional ethical committees. Written informed consent was obtained from all patients before their inclusion. This clinical trial was registered at https://clinicaltrials.gov/ (NCT00927732).

All our BrS study patients were considered at high-risk and all had an ICD implanted due to the following: previous aborted SCD or documented ventricular tachyarrhythmias (group A); previous unexplained syncope supposed to be of an arrhythmic origin (group B); spontaneous type $1 \mathrm{BrS}$ ECG pattern with a positive electrophysiological study (EPS) (group C). Patients in group A or B could display both spontaneous or drug-induced type 1 BrS ECG pattern. EPS were conducted with a maximum of three ventricular extrastimuli with a minimum coupling interval of $200 \mathrm{~ms}$ from at least one right ventricular site. EPS was considered positive if VF and/or sustained ventricular tachycardia (VT) was induced.

Patients already on daily HQ medication above 900mg or below 300mg were excluded as those with manifestations of HQ hypersensitivity [appearance of hypotension, fever, prolongation of QTc interval >40ms (arbitrarily chosen) or prolongation of QRS duration >25\%]. ${ }^{11,19,20}$ HQ hypersensitivity test (clinical and ECG monitoring for 3 hours after a single intake of HQ 300mg) was performed in every included patient not on chronic HQ therapy before.

After a 7-day washout period, patients were randomised to placebo or HQ. A crossover was performed after 18 months, separated by a second 7-day washout period. Optimal HQ dosages were assessed in each patient to achieve HQ blood level 
range from 3 to $6 \mu \mathrm{mol} / \mathrm{L}$, commonly consider as therapeutic and reported in previous studies. $^{13,16,17}$

A core lab of 3 expert physicians blinded to patient clinical and pharmacological status reviewed ECG at baseline and during follow-up. Quantitative measurements of electrocardiographic parameters were assessed at baseline, after an acute intake and on chronic HQ therapy (supplementary methods for ECG measurement's details).

Follow-up consultations, including ECG and ICD interrogation, were planned in each phase of the crossover study at 1, 6, 12 and 18 months. In case of an appropriate ICD shock, the patient was switched to phase 2 after a 7-day washout period or ended the study if he/she had already been in phase 2 .

\section{Endpoints}

The primary endpoint was the time to the first appropriate ICD shock. Secondary endpoints were evaluation of inappropriate shocks, self-terminating VT/VF episodes, death from all causes, occurrence of supra-ventricular tachycardia (SVT), syncope without arrhythmic events after ICD interrogation and adverse events under HQ therapy.

\section{Statistical Analysis}

Data were analysed with SAS packages (SAS Institute Inc., Cary, NC). Chi2 or Fisher's exact tests were used to compare categorical variables. The $t$-test, MannWhitney, Kruskall-Wallis tests were performed to test for differences in continuous parameters. Means with standard deviations or medians with quartile data are presented as appropriate. A two-sided $P$-value $<0.05$ was considered as statistically significant in all tests. 


\section{Results}

\section{Study population}

Among the 78 patients screened, 50 were randomised [mean age: $47.0 \pm 11.4$ years, $42(84 \%)$ male] as shown in Figure 1. The clinical characteristics and baseline ECG parameters for all of the 50 randomized patients and according to their subgroups are summarized in Table 1.

Twenty-six (52\%) patients were randomised to phase $1 \mathrm{HQ}$ and $24(48 \%)$ to phase 1 placebo. Among the 13 (26\%) patients who stopped therapy during phase 1,8 (62\%) were on HQ. Nine (69\%) stopped because of adverse events, which were essentially gastrointestinal $(n=6)$. Eleven $(22 \%)$ patients stopped therapy during phase 2 including $8(73 \%)$ on HQ. The main reason was adverse events $(n=10 ; 91 \%)$, which were essentially gastrointestinal $(n=5)$.

Finally, $26(52 \%)$ patients fully completed both phases (36 months) without discontinuation of medication.

\section{Occurrence of arrhythmias}

Mean follow-up was respectively 376 \pm 248 days and 377 \pm 235 days under HQ and placebo therapy.

No patient on HQ presented an appropriate ICD shock. One patient (group A) on placebo experienced an appropriate ICD shock (event rate $0.97 \%$ per year) without recurrence during the following 18 months while on HQ (900mg daily; HQ blood level: $3 \mu \mathrm{mol} / \mathrm{L}$ ), but he experienced a second appropriate ICD shock 3 days after having stopped his HQ during the washout period (after the end of phase 2). This patient was diagnosed at age 28 after an aborted SCD and presented with a spontaneous BrS type 1 ECG pattern. His specific ECG parameters under placebo then HQ therapy are shown in supplementary material Table 1. 
One self-terminating VF episode occurred in a patient (group B) while on placebo and one inappropriate ICD shock for SVT in a patient (group C) while on placebo. Fourteen patients (28\%) presented SVT during follow-up, of whom 8 (57\%) were on HQ therapy and $6(43 \%)$ on placebo $(P=0.33)$. Two $(4 \%)$ patients died during the study, one (group B) from a traumatic brain injury and the other (group A) secondary to a neuromuscular disease.

\section{HQ therapy}

The mean HQ daily dosage was $738 \pm 174 \mathrm{mg}$ with a mean HQ blood level of $3.14 \pm 0.63 \mu \mathrm{mol} / \mathrm{L}$. Twenty-nine $(58 \%)$ patients were under HQ 600mg daily, 19 (38\%) under 900mg and 2 (4\%) under 1200mg with mean HQ blood levels respectively of $3.44 \pm 0.65 \mu \mathrm{mol} / \mathrm{L}, 2.84 \pm 0.46 \mu \mathrm{mol} / \mathrm{L}$ and $3.20 \pm 0.71 \mu \mathrm{mol} / \mathrm{L}$.

Thirty-four $(68 \%)$ patients reported adverse events during their treatment with HQ. Thirteen (26\%) had to stop the medication for HQ-related side effects, which were mainly gastrointestinal $(n=10 ; 77 \%)$ but also photophobia $(n=2 ; 15 \%)$ and photosensitivity $(\mathrm{n}=1 ; 8 \%)$. Three stopped HQ for adverse events not related to HQ therapy. Side effects were significantly more frequent with HQ therapy (Table 2).

Patients who experienced side effects were on a higher mean daily dosage of HQ (768 $\pm 186 \mathrm{mg}$ vs. $675 \pm 136 \mathrm{mg} ; P=0.04)$ but no differences were found regarding age, sex, clinical presentation, ECG parameters or HQ blood levels $(3.09 \pm 0.46 \mu \mathrm{mol} / \mathrm{L}$ vs. $3.28 \pm 0.82 \mu \mathrm{mol} / \mathrm{L} ; P=0.25)$.

\section{Acute HQ-induced ECG changes}

Among the 50 randomised patients, 48 (96\%) underwent a hypersensitivity HQ test whereas $2(4 \%)$ were already on HQ therapy. QT (387 \pm 27 vs. $414 \pm 35 \mathrm{~ms}$; $P<0.0001)$, QTc intervals ( $404 \pm 29$ vs. $417 \pm 29 \mathrm{~ms} ; P=0.027)$ and Tpe max $(95 \pm 18$ vs. $107 \pm 22 \mathrm{~ms} ; P<0.001)$ were significantly longer 3 hours after an acute intake of HQ 
$300 \mathrm{mg}$. No significant changes were observed on J-point elevation. Details are provided in Table 3 and according to subgroup in supplementary material Table 2.

\section{Chronic HQ-induced ECG changes}

Among the 50 randomised patients who underwent both therapies (HQ and placebo), QT $(388 \pm 29$ vs. $411 \pm 35 \mathrm{~ms} ; P<0.0001)$, QTc intervals $(409 \pm 32$ vs. $433 \pm 37 \mathrm{~ms} ; P=0.027)$, Tpe $\max (89 \pm 15$ vs. $108 \pm 27 \mathrm{~ms} ; P<0.0001)$ and Tpe dispersion were significantly longer while on chronic HQ therapy. No significant changes were observed in J-point elevation in any of the right precordial leads. Except for QTc interval $[417 \pm 29 \mathrm{~ms}$ (acute) vs. $433 \pm 37 \mathrm{~ms}$ (chronic); $P<0.0001]$, no ECG parameters appeared to be different under acute and chronic HQ therapy. Details are provided in Table 3 and according to subgroup in supplementary material Table 3. Except for QTc $(421 \pm 35 \mathrm{~ms}$ vs. $443 \pm 36 \mathrm{~ms} ; P<0.001)$, no significant relevant differences were observed comparing patients under 600mg daily of HQ with others (>600mg daily). Details are presented in supplementary material Table 4. An example of ECG HQinduced changes is shown in Figure 2. 


\section{Discussion}

Since there was no occurrence of any ventricular arrhythmia in patients under HQ, HQ appears to be quite effective in BrS. However, statistical significance compared to placebo was not observed, principally owing to a lower arrhythmic event frequency than expected (only one patient on placebo presenting with ventricular arrhythmia) and to HQ-related adverse events, which were frequent and causing interruption of therapy in a significant number of cases.

\section{HQ-related side effects}

HQ-related side effects, especially gastrointestinal, have been broadly described in the literature but tend to be fewer than those we observed. Belhassen ${ }^{14}$ reported a $36 \%$ adverse events rate in patients on a mean daily dosage of quinidine bisulfate of $1483 \pm 240 \mathrm{mg}$. Among patients on lower HQ dosages $(618 \pm 72 \mathrm{mg} /$ day $)$, Bouzeman $^{16}$ noted a low $6 \%$ rate of major HQ intolerance which led to a discontinuance of therapy. Mizusawa ${ }^{21}$ observed no major intolerance in the 14 patients on HQ daily dosage between 300 to 600mg (mean HQ blood level: $1.55 \mu \mathrm{g} / \mathrm{mL}$ ) with reported success of $44 \%$ in preventing VF inducibility.

In our study, with a mean HQ daily dosage of $738 \pm 174 \mathrm{mg}$, we observed a larger proportion of 58\% HQ-related adverse events that led to a discontinuance of therapy in $26 \%$. Nonetheless, we were still on the lower border of our therapeutic HQ blood level range $(3.14 \pm 0.63 \mu \mathrm{mol} / \mathrm{L})$. One could argue that the lower the dosage used, the lower the side effects rate, but lower HQ efficacy may also be expected. This lower HQ dosage have been suggested to be efficient in case series, but without further evidences, the difficult question of defining optimal HQ daily dosages remain to be assessed ${ }^{22}$. 
Apart from higher HQ dosage, we found no differences between patients who suffered from adverse events and others. Thus, our data did not support a genotype or phenotype relation with side-effects.

\section{HQ-induced ECG changes}

Aside from its $\mathrm{I}_{\mathrm{Na}}$ and $\mathrm{I}_{\mathrm{Kr}}$ blocking effect, HQ presents with an $\mathrm{I}_{\mathrm{to}}$ blocking effect that has been suggested to support it potential therapeutic role in patients with $\mathrm{BrS}^{13,23}$. Indeed, according to Antzelevitch et al., ${ }^{23}$ the transmural heterogeneity of $\mathrm{I}_{\mathrm{to}}$ current, which induces repolarization heterogeneity, plays a key role in the occurrence of type $1 \mathrm{BrS}$ ECG pattern as well as in the arrythmogenicity by facilitating phase 2 re-entry ${ }^{2,24}$. Tpe has been used as an ECG marker of this transmural repolarization dispersion $^{25}$ and appears to be a useful tool to evaluate repolarization processes and the effects of HQ in BrS patients. A prolonged Tpe interval should be correlated with increased transmural repolarization heterogeneity that may enhance the substrate for phase 2 re-entry. Confirming this hypothesis, according to Maury, ${ }^{26}$ this prolonged Tpe and Tpe max denote a higher risk of arrhythmic events in BrS patients.

The present study showed that HQ-induced ECG changes appear promptly after an acute intake and are maintained under chronic therapy. This correlates the clinical efficacy of HQ observed during electrical storms in $\mathrm{BrS}$ patients ${ }^{27}$. We expected a reduction of repolarization heterogeneity in BrS patients who underwent HQ therapy. However, although HQ lengthened QT and QTc interval, it also increased the repolarization dispersion as evaluated by the Tpe and Tpe max. Additionally, in opposition to previous clinical reports, ${ }^{28}$ we did not find any significant effect on J-point elevation.

This effect was considered as unexpected based on the idea that $\mathrm{BrS}$ pathophysiology involved only a repolarization disorder. ${ }^{23}$ However, as we now 
know, repolarization and depolarisation disorders are both involved. ${ }^{29}$ Therefore, these ECG modifications could denote a more complex role than simply a selective and exclusive $\mathrm{I}_{\mathrm{to}}$ blocking effect of $\mathrm{HQ}$ in $\mathrm{BrS}$ patients. Indeed, $\mathrm{I}_{\mathrm{Kr}}$ blocking effect has been demonstrated to prolong Tpe interval with a similar but smaller effect on ST segment interval ${ }^{19}$. Interestingly, the multi-ion channel block of quinidine is concentration-dependent and begins with a $\mathrm{I}_{\mathrm{Kr}}$ blocking effect before appearance of significant block in other sodium, calcium and potassium channel including $\mathrm{I}_{\mathrm{to}}{ }^{30}$. This could explain the increase in Tpe interval without modification of $\mathbf{J}$ wave amplitude that we observed in our study. Among previous studies about BrS, both low and high dosages of HQ have been used, generating various effects on patient's ECGs. In our study, HQ-induced ECG changes were similar (except for QTc) regardless of daily HQ dosage.

Altogether, this suggests that the global ionic effect of HQ may explain the variability in ECG modifications among studies. ${ }^{13,23}$ As a consequence, assuming HQ is efficient to prevent arrhythmia in $\mathrm{BrS}$, its effect does not seem to be only and directly due to $\mathrm{I}_{\text {to }}$ inhibition.

\section{Study Limitations}

When the QUIDAM study was designed, only few databases that included a large number of patients were available and EPS to test for VF inducibility was commonly used as a tool for risk stratification ${ }^{6,31}$. Thence, we expected an arrhythmic event rate to be as high as $1 \%$ monthly in our selected population. This was weighted by our proper evaluation data of arrhythmic risk in patients with $\mathrm{BrS}$ which was subsequently published in the FINGER study, ${ }^{6}$ but that was still overestimated in comparison to current knowledge. 
According to Hermida ${ }^{13}$ et al., one could initially consider a risk reduction of arrhythmic events up to $70 \%$ with HQ with $10 \%$ adverse events leading to discontinuation of therapy. On this basis, with an $\alpha=5 \%$ and $\beta=20 \%$, and based on expected arrhythmic rate at study onset, 200 patients were thought necessary to reach statistical significance within a 24-month follow-up. This was extended to 36 months to reach statistical significance due to the lower than expected arrhythmic event rate. However, when both were combined, the real arrhythmic event rate and HQ-related side effects leading to discontinuation of therapy, the estimated sample size to reach statistical difference was evaluated as high as 1,800 patients. This extremely high and not reasonably achievable number led to the premature termination of the QUIDAM study.

\section{The future of HQ}

Despite previous encouraging clinical and experimental studies, ${ }^{13,14,23}$ the QUIDAM study was not able to provide evidence-based data to support its efficacy and safety in high-risk BrS patients. The use of HQ has been suggested in lower-risk Brs patients. ${ }^{16,17}$ However, considering the low arrhythmic event rate and a similar HQ-related side-effect rate, demonstration of a significant effect appears unachievable in such population.

Still, as shown by our patient who experienced one (two if wash-out period is included) appropriate ICD shock(s) on placebo, our study supports the HQ individual efficacy. Retrospective studies have reported the well-tolerance and the likely efficiency of long-term HQ therapy ${ }^{17,32}$. Anguera ${ }^{33}$ et al. noted that quinidine could be useful to reduce, but not supress, the burden of ventricular arrhythmias with still few patients who experienced ICD shocks. 
Considering the progress of defibrillation devices leading to less ICD-related complications (especially with the sub-cutaneous ICD), the development of catheter ablation in BrS patients and the virtual impossibility to demonstrate the efficacy of HQ therapy, it is likely that its use will remain restricted to secondary prevention in patients already implanted with an ICD or who refuses or has no access to one.

According to current evidence based data, HQ could not be considered as an alternative for ICD implant in patients with high-risk BrS, even considering the high rate of ICD-related complications in such population. Define precise daily HQ dose and characteristics of patients whom benefit from HQ therapy would be of a great help.

We advise to consider, if available, the use of an individual well tolerated HQ dosage in $\mathrm{BrS}$ patients with ICD and recurrent ventricular arrhythmias. If such a therapy should fail or be badly tolerated, catheter ablation might be an adjuvant. However, several studies are ongoing and will provide data in the future to better place catheter ablation among the therapeutic arsenal for BrS patients. ${ }^{34}$

Finally, in the paediatric BrS population where an ICD implant could be challenging and HQ appears to be well tolerated, this therapy could be a temporary alternative. $^{35}$ 


\section{Conclusion}

The QUIDAM study was the first prospective randomized double-blind study aiming to provide strong data to support HQ use in the management of high-risk BrS patients. The conductive idea was to be capable of offering a safe alternative to ICD implants. Unfortunately, frequent HQ-related side effects and rare arrhythmic events have made it difficult to conduct large studies to prove HQ efficacy. This has led to a premature termination of the QUIDAM study without demonstrating the efficacy of this drug. According to current data, HQ could not be considered as an alternative to ICD implantation in high-risk patients with $\mathrm{BrS}$.

However, we did observe ECG changes under therapy such as lengthening of the Tpe interval with no effect on J-point elevation, which suggest a more complex role than a selective and exclusive $\mathrm{I}_{\text {to }}$ blocker effect of $\mathrm{HQ}$ in $\mathrm{BrS}$ patients. This supports the idea that $\mathrm{BrS}$ pathophysiology involves more complex mechanisms than only a repolarization disorder.

Regardless of these shadow areas, these considerations should not stop its use in daily clinical practice, especially for the management of $\mathrm{BrS}$ patients with recurrent ventricular arrhythmia or electrical storms. 


\section{$\underline{\text { Acknowledgements }}$}

We thank all the patients who agreed to be involved on this study as the "Centre de reference des maladies rythmiques héréditaires" for their help.

This study was performed with grant from Health French Ministry (clinical research hospital program BRD/06/02-D-1; 2005). 


\section{References}

1. Brugada P, Brugada J: Right bundle branch block, persistent ST segment elevation and sudden cardiac death: a distinct clinical and electrocardiographic syndrome. A multicenter report. J Am Coll Cardiol 1992; 20:1391-1396.

2. Antzelevitch $\mathrm{C}: \mathrm{J}$ wave syndromes: Molecular and cellular mechanisms. J Electrocardiol 2013; 46:510-518.

3. Le Scouarnec S, Karakachoff M, Gourraud J-B, et al.: Testing the burden of rare variation in arrhythmia-susceptibility genes provides new insights into molecular diagnosis for Brugada syndrome. Hum Mol Genet 2015; 24:2757-2763.

4. Bezzina CR, Barc J, Mizusawa Y, et al.: Common variants at SCN5ASCN10A and HEY2 are associated with Brugada syndrome, a rare disease with high risk of sudden cardiac death. Nat Genet 2013; 45:1044-1049.

5. Gourraud J-B, Barc J, Thollet A, Le Scouarnec S, Le Marec H, Schott J-J, Redon R, Probst V: The Brugada syndrome: A rare arrhythmia disorder with complex inheritance. Front Cardiovasc Med 2016; 3:9.

6. Probst V, Veltmann C, Eckardt L, et al.: Long-term prognosis of patients diagnosed with Brugada syndrome: Results from the FINGER Brugada syndrome registry. Circulation 2010; 121:635-643.

7. Adler A, Rosso R, Chorin E, Havakuk O, Antzelevitch C, Viskin S: Risk stratification in Brugada syndrome: Clinical characteristics, electrocardiographic parameters, and auxiliary testing. Heart Rhythm 2016; 13:299-310.

8. Probst V, Chatel S, Gourraud J-B, Marec HL: Risk stratification and therapeutic approach in Brugada syndrome. Arrhythmia Electrophysiol Rev 2012; $1: 17-21$.

9. Sacher F, Probst V, Maury P, et al:: Outcome after implantation of a cardioverter-defibrillator in patients with Brugada syndrome: A multicenter studyPart 2. Circulation 2013; 128:1739-1747.

10. Nademanee K: Defibrillator versus beta-blockers for unexplained death in Thailand (DEBUT): A randomized clinical trial. Circulation 2003; 107:2221-2226.

11. Wood AJ, Grace AA, Camm AJ: Quinidine. N Engl J Med 1998; 338:35-45.

12. Belhassen B, Viskin S, Fish R, Glick A, Setbon I, Eldar M: Effects of electrophysiologic-guided therapy with Class IA antiarrhythmic drugs on the longterm outcome of patients with idiopathic ventricular fibrillation with or without the Brugada syndrome. J Cardiovasc Electrophysiol 1999; 10:1301-1312.

13. Hermida J-S, Denjoy I, Clerc J, Extramiana F, Jarry G, Milliez P, Guicheney P, Di Fusco S, Rey J-L, Cauchemez B, Leenhardt A: Hydroquinidine therapy in Brugada syndrome. J Am Coll Cardiol 2004; 43:1853-1860.

14. Belhassen B, Glick A, Viskin S: Efficacy of quinidine in high-risk patients with Brugada syndrome. Circulation 2004; 110:1731-1737.

15. Viskin S, Wilde AAM, Tan HL, Antzelevitch C, Shimizu W, Belhassen B: Empiric quinidine therapy for asymptomatic Brugada syndrome: Time for a prospective registry. Heart Rhythm 2009; 6:401-404.

16. Bouzeman A, Traulle S, Messali A, Extramiana F, Denjoy I, Narayanan K, Marijon E, Hermida J-S, Leenhardt A: Long-term follow-up of asymptomatic Brugada patients with inducible ventricular fibrillation under hydroquinidine. Europace 2014; 16:572-577.

17. Belhassen B, Rahkovich M, Michowitz Y, Glick A, Viskin S: Management of Brugada syndrome: thirty-three-year experience using electrophysiologically guided therapy with Class 1A antiarrhythmic drugs. Circ Arrhythm Electrophysiol 2015; 
8:1393-1402.

18. Probst V, Gourraud J-B: Quinidine in Brugada syndrome: still a long way to go... Circ Arrhythm Electrophysiol 2015; 8:1309-1310.

19. Johannesen L, Vicente J, Mason JW, et al.: Differentiating drug-induced multichannel block on the electrocardiogram: randomized study of dofetilide, quinidine, ranolazine, and verapamil. Clin Pharmacol Ther 2014; 96:549-558.

20. Roden DM: Predicting drug-induced QT prolongation and torsades de pointes. J Physiol 2016; 594:2459-2468.

21. Mizusawa Y, Sakurada H, Nishizaki M, Hiraoka M: Effects of low-dose quinidine on ventricular tachyarrhythmias in patients with Brugada syndrome: lowdose quinidine therapy as an adjunctive treatment. J Cardiovasc Pharmacol 2006; 47:359-364.

22. Márquez MF, Bonny A, Hernández-Castillo E, De Sisti A, Gómez-Flores J, Nava S, Hidden-Lucet F, Iturralde P, Cárdenas M, Tonet J: Long-term efficacy of low doses of quinidine on malignant arrhythmias in Brugada syndrome with an implantable cardioverter-defibrillator: a case series and literature review. Heart Rhythm 2012; 9:1995-2000.

23. Yan G-X, Antzelevitch C: Cellular basis for the Brugada syndrome and other mechanisms of arrhythmogenesis associated with ST-segment elevation. Circulation 1999; 100:1660-1666.

24. Gaborit N, Wichter T, Varro A, Szuts V, Lamirault G, Eckardt L, Paul M, Breithardt G, Schulze-Bahr E, Escande D, Nattel S, Demolombe S: Transcriptional profiling of ion channel genes in Brugada syndrome and other right ventricular arrhythmogenic diseases. Eur Heart J 2009; 30:487-496.

25. Antzelevitch C, Yan GX, Shimizu W: Transmural dispersion of repolarization and arrhythmogenicity: the Brugada syndrome versus the long QT syndrome. J Electrocardiol 1999; 32 Suppl:158-165.

26. Maury P, Sacher F, Gourraud J-B, et al.: Increased Tpeak-Tend interval is highly and independently related to arrhythmic events in Brugada syndrome. Heart Rhythm 2015; 12:2469-2476.

27. Probst V, Evain S, Gournay V, Marie A, Schott J-J, Boisseau P, Le Marec H: Monomorphic ventricular tachycardia due to Brugada syndrome successfully treated by hydroquinidine therapy in a 3-year-old child. J Cardiovasc Electrophysiol 2006; 17:97-100.

28. Alings M, Dekker L, Sadée A, Wilde A: Quinidine induced electrocardiographic normalization in two patients with Brugada syndrome. Pacing Clin Electrophysiol 2001; 24:1420-1422.

29. Tokioka K, Kusano KF, Morita H, Miura D, Nishii N, Nagase S, Nakamura K, Kohno K, Ito H, Ohe T: Electrocardiographic parameters and fatal arrhythmic events in patients with Brugada syndrome. J Am Coll Cardiol 2014; 63:2131-2138.

30. Vicente J, Johannesen L, Mason JW, Crumb WJ, Pueyo E, Stockbridge N, Strauss DG: Comprehensive $\mathrm{T}$ wave morphology assessment in a randomized clinical study of dofetilide, quinidine, ranolazine, and verapamil. J Am Heart Assoc 2015; 4. 31. Brugada J, Brugada R, Antzelevitch C, Towbin J, Nademanee K, Brugada P: Long-term follow-up of individuals with the electrocardiographic pattern of right bundle-branch block and ST-segment elevation in precordial leads V1 to V3. Circulation 2002; 105:73-78.

32. Adler A, Olde Nordkamp L, Crotti L, et al.: Empiric quinidine for asymptomatic Brugada syndrome-preliminary results of an international registry. Heart Rhythm 2012; 9:1918-1919. 
33. Anguera I, García-Alberola A, Dallaglio P, Toquero J, Pérez L, Martínez JG, Peinado R, Rubín JM, Brugada J, Cequier A: Shock reduction with long-term quinidine in patients with Brugada syndrome and malignant ventricular arrhythmia episodes. J Am Coll Cardiol 2016; 67:1653-1654.

34. Nademanee K, Hocini M, Haïssaguerre M: Epicardial substrate ablation for Brugada syndrome. Heart Rhythm 2017; 14:457-461.

35. Andorin A, Behr ER, Denjoy I, et al.: Impact of clinical and genetic findings on the management of young patients with Brugada syndrome. Heart Rhythm 2016; 13:1274-1282. 


\section{Figure legends}

Figure 1: Flow-chart of the QUIDAM study.

Figure 2: Twelve-lead ECG with no medication (baseline), after an acute intake of hydroquinidine (HQ) and under chronic HQ therapy. An increased QTc and Tpe max was observed while on both HQ therapies. ECG-speed $25 \mathrm{~mm} / \mathrm{s}$ and voltage $10 \mathrm{~mm} / \mathrm{mV}$. 


\section{Tables}

Table 1: Clinical characteristics and ECG parameters on inclusion. Group A: past history of SCD; Group B: past history of syncope; Group C: asymptomatic with spontaneous type 1 ECG pattern and positive electrophysiological study.

\begin{tabular}{|c|c|c|c|c|}
\hline & $\begin{array}{l}\text { Group A } \\
n=6(12 \%)\end{array}$ & $\begin{array}{l}\text { Group B } \\
n=26(52 \%)\end{array}$ & $\begin{array}{c}\text { Group C } \\
n=18(36 \%)\end{array}$ & $\begin{array}{c}\text { Total } \\
n=50(100 \%)\end{array}$ \\
\hline \multicolumn{5}{|l|}{ Clinical characteristics } \\
\hline Age on diagnosis, years & $43.7 \pm 12.6$ & $45.5 \pm 11.9$ & $50.6 \pm 9.8$ & $47.0 \pm 11.4$ \\
\hline Male, $n(\%)$ & $5(83)$ & $22(85)$ & $15(83)$ & $42(84)$ \\
\hline Family history of SCD, $n(\%)$ & 0 & $6(23)$ & $9(50)$ & $15(30)$ \\
\hline Spontaneous Type 1 ECG pattern, $n(\%)$ & $5(83)$ & $13(50)$ & $18(100)$ & $36(72)$ \\
\hline Dual Chamber ICD, $n(\%)$ & 0 & $2(8)$ & $1(5)$ & $3(6)$ \\
\hline VF zone >200 bpm, $n(\%)$ & $6(100)$ & $23(88)$ & $18(100)$ & $47(94)$ \\
\hline Presence of a VT zone, $n(\%)$ & $3(50)$ & $3(12)$ & $5(28)$ & $11(22)$ \\
\hline SCN5A mutation, $(\mathrm{n}=43), n(\%)$ & $0 / 5(0)$ & $4 / 22(18)$ & $5 / 16(31)$ & $9 / 43(21)$ \\
\hline \multicolumn{5}{|l|}{ ECG parameters on inclusion } \\
\hline Heart Rate (bpm) & $72 \pm 11$ & $72 \pm 10$ & $67 \pm 10$ & $70 \pm 11$ \\
\hline $\mathrm{PR}(m s)$ & $180 \pm 13$ & $190 \pm 32$ & $180 \pm 36$ & $185 \pm 32$ \\
\hline $\mathrm{QRS}(m s)$ & $108 \pm 11$ & $112 \pm 22$ & $102 \pm 36$ & $108 \pm 21$ \\
\hline $\mathrm{QT}(m s)$ & $393 \pm 48$ & $382 \pm 32$ & $383 \pm 31$ & $383 \pm 33$ \\
\hline QTc Bazett $(m s)$ & & $425 \pm 37$ & $397 \pm 37$ & $415 \pm 39$ \\
\hline Maximum J-point elevation $(\mathrm{mm})$ & $4.0 \pm 2.3$ & $3.5 \pm 1.4$ & $3.2 \pm 1.2$ & $3.5 \pm 1.5$ \\
\hline
\end{tabular}

SCD: sudden cardiac death; ECG: electrocardiogram; ICD: implantable cardioverter defibrillator: VF: ventricular fibrillation; VT: ventricular tachycardia 
Table 2: Adverse events in the randomised population $(\mathrm{n}=50)$ of the QUIDAM study according to placebo or hydroquinidine therapy.

\begin{tabular}{|c|c|c|c|}
\hline & Placebo & HQ & $P$-value \\
\hline Duration of therapy, days & $377 \pm 235$ & $376 \pm 248$ & 0.23 \\
\hline AE leading to stop therapy, $n(\%)$ & $3(6)$ & $16(32)$ & 0.002 \\
\hline Gastrointestinal, $n(\%)$ & $1(2)$ & $10(20)$ & 0.008 \\
\hline Other existing $\mathrm{AE}$ under $\mathrm{HQ}, n(\%)$ & 0 & $3(6)$ & 0.24 \\
\hline photophobia & 0 & $2(4)$ & - \\
\hline photosensitivity & 0 & $1(2)$ & - \\
\hline AE unrelated to $\mathrm{HQ}, n(\%)$ & 2(4) & $3(6)$ & 1 \\
\hline AE not leading to stop therapy, $n(\%)$ & $5(10)$ & $18(36)$ & 0.004 \\
\hline Gastrointestinal, $n(\%)$ & 2(4) & $16(32)$ & 0.0004 \\
\hline Other existing $\mathrm{AE}$ on $\mathrm{HQ}, n(\%)$ & $3(6)$ & $9(18)$ & 0.12 \\
\hline photophobia & 0 & 2(4) & - \\
\hline photosensitivity & 0 & $2(4)$ & - \\
\hline tinnitus & 0 & $2(4)$ & - \\
\hline headache & 0 & $1(2)$ & - \\
\hline vertigo & $1(2)$ & 1(2) & - \\
\hline fatigue & 2(4) & $1(2)$ & - \\
\hline AE unrelated to $\mathrm{HQ}, n(\%)$ & 0 & $7(14)$ & 0.01 \\
\hline
\end{tabular}

AE: adverse events; $H Q$ : hydroquinidine 
Table 3: Standard and repolarization dispersion ECG parameters measured before

(Before HQ), 3 hours after (Acute HQ) a 300mg intake of hydroquinidine, under placebo and chronic hydroquinidine therapy.

\begin{tabular}{|c|c|c|c|c|c|}
\hline & $\begin{array}{c}\text { Before HQ } \\
(n=48)\end{array}$ & $\begin{array}{c}\text { Acute HQ } \\
(n=48)\end{array}$ & $\begin{array}{c}\text { Placebo } \\
(n=50)\end{array}$ & $\begin{array}{c}\text { Chronic HQ } \\
\qquad(n=50)\end{array}$ & P-value \\
\hline \multicolumn{6}{|l|}{ Standard ECG parameters } \\
\hline Heart Rate $(\mathrm{bpm})$ & $67 \pm 10^{*}$ & $62 \pm 10 * \dagger$ & $68 \pm 10$ & $69 \pm 10 \dagger$ & $* 0.032 ; \dagger 0.0004$ \\
\hline $\mathrm{PR}(m s)$ & $182 \pm 31$ & $185 \pm 31$ & $182 \pm 36$ & $186 \pm 31$ & - \\
\hline $\mathrm{QRS}(m s)$ & $103 \pm 17$ & $104 \pm 18$ & $103 \pm 17$ & $103 \pm 16$ & - \\
\hline $\mathrm{QT}(m s)$ & $387 \pm 27 *$ & $414 \pm 35^{*}$ & $388 \pm 29 \dagger$ & $411 \pm 35 \dagger$ & $* \dagger<0.0001$ \\
\hline QTc Bazett $(m s)$ & $404 \pm 29 *$ & $417 \pm 29 * \dagger$ & $409 \pm 32 \ddagger$ & $433 \pm 37 \dagger \neq$ & $* 0.027 ; \dagger+<0.0001$ \\
\hline Maximum J-point elevation $(\mathrm{mm})$ & $1.6 \pm 1.5$ & $1.7 \pm 1.6$ & $1.8 \pm 1.4$ & $1.8 \pm 1.5$ & - \\
\hline \multicolumn{6}{|l|}{ Tpe $(m s)$} \\
\hline V1 & $79.3 \pm 19.9$ & $84.1 \pm 24.5$ & $69.7 \pm 16.0^{*}$ & $77.4 \pm 20.9 *$ & $* 0.0055$ \\
\hline $\mathrm{V} 2$ & $85.2 \pm 19.4^{*}$ & $91.1 \pm 25.0^{*}$ & $74.5 \pm 16.8 \dagger$ & $87.2 \pm 21.5 \dagger$ & $* 0.046 ; \uparrow<0.0001$ \\
\hline V3 & $82.5 \pm 15.2 *$ & $92.0 \pm 18.8^{*}$ & $80.0 \pm 17.1 \dagger$ & $95.7 \pm 29.5 \dagger$ & $* 0.002 ; \dagger<0.0001$ \\
\hline V4 & $79.4 \pm 15.7 *$ & $88.6 \pm 20.5^{*}$ & $78.6 \pm 13.8 \dagger$ & $87.8 \pm 25.1 \dagger$ & $* 0.002 ; \dagger 0.0013$ \\
\hline V5 & $76.6 \pm 16.6^{*}$ & $87.2 \pm 23.6^{*}$ & $75.4 \pm 15.2 \dagger$ & $83.8 \pm 23.9 \dagger$ & $*<0.001 ; \dagger 0.0028$ \\
\hline V6 & \multicolumn{2}{|c|}{$73.4 \pm 17.0 * \quad 83.4 \pm 20.4 *$} & $69.5 \pm 12.7 \dagger$ & $79.0 \pm 19.1 \dagger$ & $* 0.001 ; \dagger<0.0001$ \\
\hline Tpe/QTc & & & & & - \\
\hline $\mathrm{V} 1$ & $0.205 \pm 0.046$ & $0.205 \pm 0.046^{*}$ & $0.176 \pm 0.040$ & $0.181 \pm 0.043^{*}$ & 0.01 \\
\hline $\mathrm{V} 2$ & $0.218 \pm 0.032$ & $0.218 \pm 0.032$ & $0.192 \pm 0.040$ & $0.208 \pm 0.048$ & - \\
\hline V3 & $0.222 \pm 0.037$ & $0.222 \pm 0.037$ & $0.206 \pm 0.046$ & $0.225 \pm 0.064$ & - \\
\hline $\mathrm{V} 4$ & $0.214 \pm 0.036$ & $0.214 \pm 0.036$ & $0.201 \pm 0.033$ & $0.207 \pm 0.053$ & - \\
\hline V5 & $0.205 \pm 0.039$ & $0.214 \pm 0.047 *$ & $0.193 \pm 0.034$ & $0.196 \pm 0.048^{*}$ & $* 0.04$ \\
\hline V6 & $0.197 \pm 0.040$ & $0.209 \pm 0.048 *$ & $0.180 \pm 0.030$ & $0.187 \pm 0.038^{*}$ & $* 0.004$ \\
\hline Tpe dispersion $(m s)$ & $31.0 \pm 15.8$ & $36.0 \pm 19.0$ & $29.6 \pm 13.1^{*}$ & $42.3 \pm 23.6^{*}$ & $*<0.0001$ \\
\hline Tpe max $(m s)$ & $94.8 \pm 18.3^{*}$ & $106.6 \pm 22.4^{*}$ & $89.4 \pm 15.2 \dagger$ & $107.7 \pm 26.6 \dagger$ & $*<0.001 ; \dagger<0.0001$ \\
\hline
\end{tabular}

No comparisons were made between acute $H Q$ and Placebo ECG: electrocardiogram; $H Q$ : hydroquinidine 
Figure 1

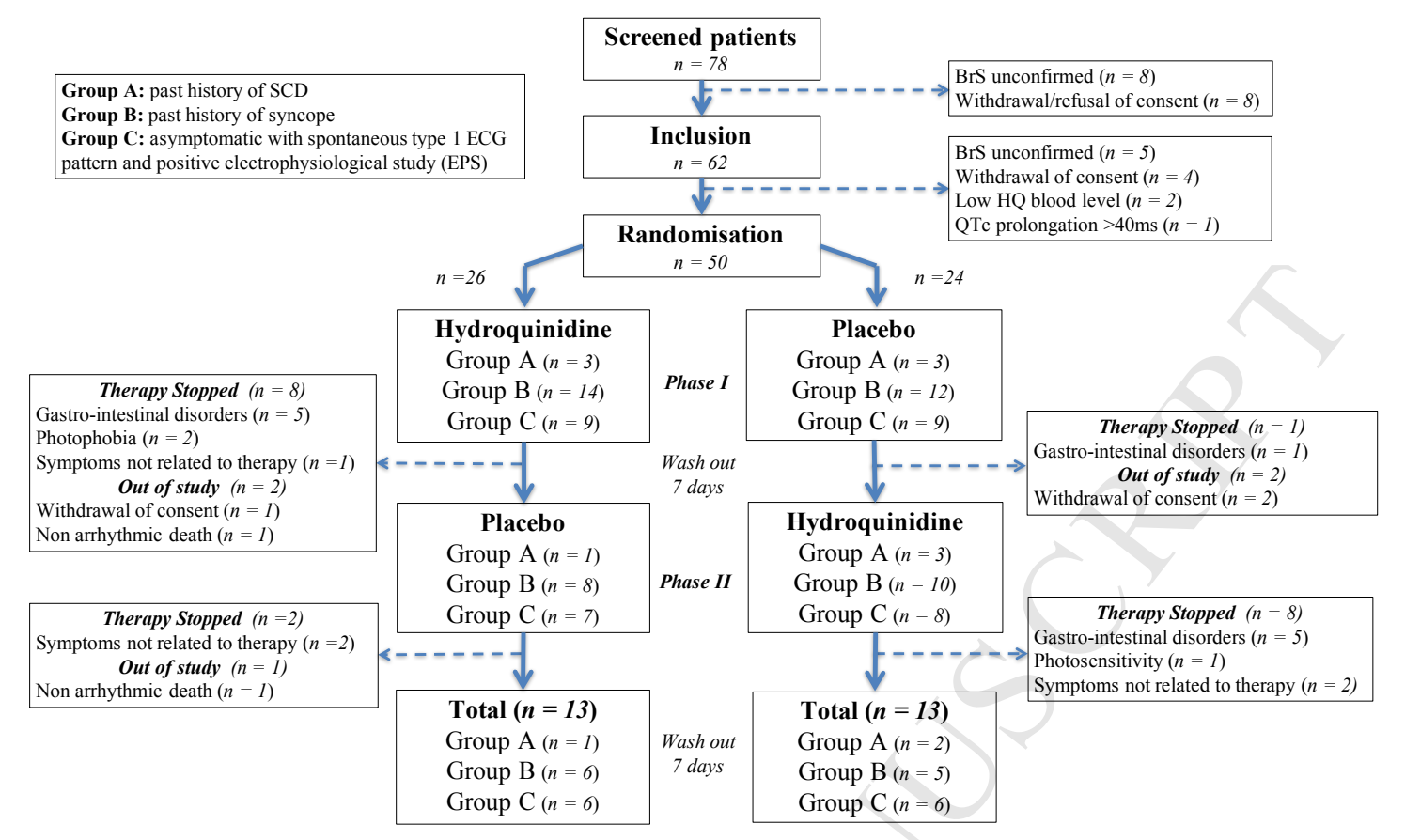




\section{Figure 2}

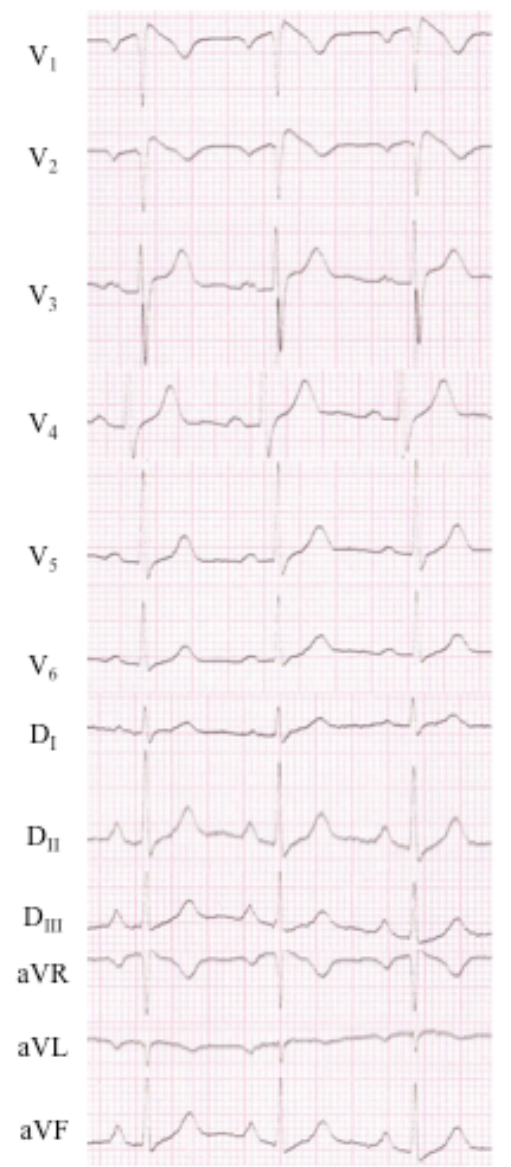

Baseline

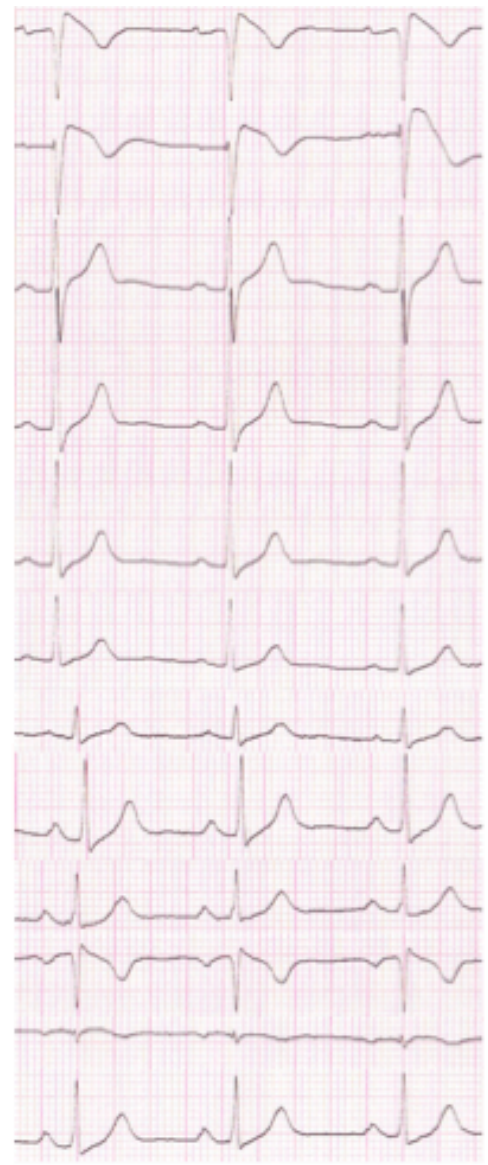

Acute HQ therapy

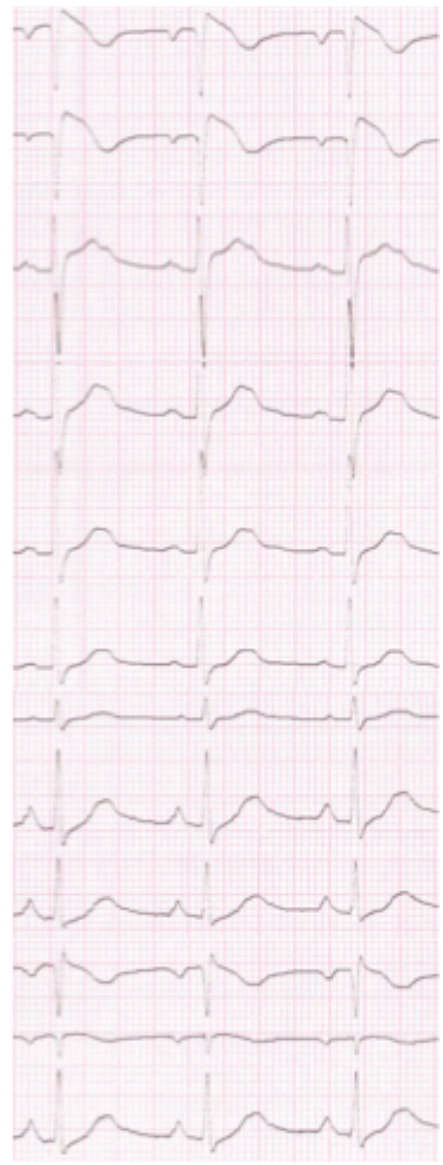

Chronic HQ therapy 